\title{
PENGEMBANGAN GEOPRODUK GEOPARK TAMBORA UNTUK PEMBERDAYAAN MASYARAKAT LOKAL BERBASIS INTERPRETASI GEOLOGI
}

\author{
Alpiana1), Diah Rahmawati ${ }^{1)}$, Joni Safaat Adiansyah ${ }^{1)}$ \\ ${ }^{1)}$ Program Studi Teknik Pertambangan, Fakultas Teknik, Universitas Muhammadiyah Mataram, Mataram, Indonesia \\ Corresponding author : Alpiana \\ E-mail : alpiana0901@gmail.com
}

Diterima 10 Maret 2020, Disetujui 24 Maret 2020

\begin{abstract}
ABSTRAK
Geopark atau taman Bumi merupakan sebuah kawasan yang di dalamnya memiliki keunikan geologi (outstanding geology), yaitu nilai arkeologi, ekologi dan budaya, dengan mengikut sertakan masyarakat setempat untuk berperan dalam melindungi dan meningkatkan fungsi warisan alam. Geopark Tambora merupakan salah satu Geopark Nasional diantara 9 (sembilan) Geopark nasional lainnya. Kawasan Geopark Tambora berada di Provinsi NTB. Geopark Tambora yang berada di Pulau Sumbawa melingkupi Kabupaten Bima dan Kabupaten Dompu, meliputi Kecamatan Pekat, Kempo, Tambora, Sanggar dan sebagian wilayah Kecamatan Manggalewa. Dalam rangka melakukan upaya konservasi warisan geologi dan sekaligus memperoleh manfaat yang berkelanjutan dari Geopark Tambora diperlukan suatu perencanaan dan pemberdayaan kepada masyarakat. Pemberdayaan masyarakat lokal merupakan hal yang sangat perlu dilakukan, karena partisipasi masyarakat sangatlah penting. Geopark bertujuan untuk memberikan manfaat untuk peningkatan kesejahteraan masyarakat disekitarnya. Kegiatan Pengabdian pada Masyarakat dilakukan di kawasan Geopark Tambora yaitu di Desa Kempo, Kecamatan Kempo Kabupaten Dompu. Metode pelaksanaan Pengabdian Pada Masyarakat dengan tahapan : Melakukan pelatihan dalam pembuatannya kepada kelompok wanita di Desa Kempo, Melakukan pemberian nama sesuai dengan interpretasi geologi terhadap geokuliner yang dihasilkan dan Pelatihan pengemasan geokuliner dan bentuk promosi yang bisa dipasarkan melalui Geopark Corner. Kesimpulan dalam kegiatan pengabdian pada masyarakat ini yaitu pengembangan geoproduk berbasis masyarakat lokal dengan interpretasi geologi yaitu : Kegiatan pelatihan mendapatkan dukungan dari peserta pelatihan di Desa Kempo, Hasil pelatihan akan menjadi produk di Geopark Corner Geopark Tambora, dan Dengan adanya geokuliner diharapkan peran perempuan Desa Kempo akan mendapatkan keuntungan ekonomi.
\end{abstract}

Kata kunci: geopark; pemberdayaan; masyarakat; geokuliner.

\begin{abstract}
Geopark or park of the Earth is an area in which it has a unique geology, namely archeological, ecological and cultural values, by involving local people to play a role in protecting and enhancing the function of natural heritage. Tambora Geopark is one of the National Geopark among 9 (nine) other national Geoparks. Tambora Geopark region is in the NTB Province. Tambora Geopark located on Sumbawa Island covers Bima and Dompu Regencies, including Pekat, Kempo, Tambora, Sanggar Districts and parts of the Manggalewa District. In order to make efforts to conserve geological heritage and at the same time obtain sustainable benefits from Tambora Geopark, planning and empowerment of the community is needed. Empowerment of local communities is a very necessary thing to do, because community participation is very important. Geopark aims to provide benefits for improving the welfare of the surrounding community. Community Service Activities are carried out in the Tambora Geopark area, namely in the Village of Kempo, Kempo District, Dompu Regency. Community service implementation method with stages: Conduct training in making it to a group of women in Kempo Village, Give a name in accordance with the geological interpretation of the resulting geoculiner and geoculiner packaging training and promotional forms that can be marketed through Geopark Corner. The conclusion in this community service activity is the development of local community-based geoproducts with geological interpretation, namely: Training activities get support from training participants in Kempo Village, the results of the training will be a product at the Geopark Tambora Geopark, and with the presence of a geokuliner the role of women in Kempo Village will be get economic benefits.
\end{abstract}

Keywords: geopark; empowerment; public; geoculiner. 


\section{PENDAHULUAN}

Geopark atau Taman Bumi berdasarkan (UNESCO, 2004) merupakan sebuah kawasan yang di dalamnya memiliki keunikan geologi (outstanding geology), yaitu nilai arkeologi, ekologi dan budaya, dengan mengikut sertakan masyarakat setempat untuk berperan dalam melindungi dan meningkatkan fungsi warisan alam. Diharapkan bahwa Geopark akan memberikan nilai konservasi dan bisa menyejahterakan masyarakat kawasan Geopark. Dalam pengembangan kawasan Geopark, harus memiliki 3 (tiga) unsur yaitu keragaman geologi (geodiversity), keragaman biologi (Biodiversity), dan keragaman budaya (cultural diversity), sehingga ketiga unsur dalam Geopark ini harus berlangsung (Dossier Geopark Tambora, 2017).

Geopark diperkenalkan sebagai strategi baru untuk memperoleh pembangunan berkelanjutan dan lebih meningkatkan status sosial ekonomi melalui partisipasi masyarakat lokal dalam kegiatan Geoaprk secara terus menerus (Farsani et al, 2011). Definisi lainnya menurut Fauzi dan Misni (2016) bahwa konsep Geopark yang memperkenalkan membangun nilai sejarah negara sekaligus melindungi semua aset yang tak ternilai dan telah menjadi tujuan ekowisata yang menarik. sedangkan menurut Komoo (2010) konsep Geopark telah berkembang dan memperkenalkan gagasan dari kawasan lindung menjadi alat pembangunan untuk kawasan yang memiliki nilai jual. konsep Geopark difokuskan dan dianggap memiliki keseimbangan antara kegiatan konservasi warisan geologi, geotourism dan kesejahteraan masyarakat setempat.

Geopark Tambora merupakan salah satu Geopark Nasional diantara 9 (sembilan) Geopark nasional lainnya. Kawasan Geopark Tambora berada di Provinsi NTB. Provinsi NTB merupakan satu-satunya Provinsi yang memiliki 2 Geopark yaitu Rinjani Lombok Unesco Global Geopark yang sudah berstatus UGG dan Geopark Tambora dengan status Geopark Nasional.

Geopark Tambora yang berada di Pulau Sumbawa melingkupi Kabupaten Bima dan Kabupaten Dompu, meliputi Kecamatan Pekat, Kempo, Tambora, Sanggar dan sebagian wilayah Kecamatan Manggalewa. Geopark Tambora memiliki nilai geologi yang tinggi yang berbeda dengan Geopark lainnya. Geopark Tambora mengangkat tagline "The Most Historical Eruption in The World" dimana nilai sejarah letusan Gunung Tambora pada tahun 1815 merupakan letusan dengan skala VEI 7 yang tercatat dengan lengkap. Dari hasil letusannya dapat diketahui memusnahkan 3
Kerajaan di sekitar Gunung Tambora yaitu Kerajaan Pekat, Kerajaan Sanggar, dan Kerajaan Tambora. Letusan Tambora menyebabkan pembentukan bentang alam yang unik, dengan flora fauna yang khas dan tentunya budaya yang tetap melekat dalam masyarakat di Kawasan Tambora.

Dalam rangka melakukan upaya konservasi warisan geologi dan sekaligus memperoleh manfaat yang berkelanjutan dari Geopark Tambora diperlukan suatu perencanaan dan pemberdayaan kepada masyarakat. Pemberdayaan masyarakat lokal merupakan hal yang sangat perlu dilakukan, karena partisipasi masyarakat sangatlah penting. Geopark bertujuan untuk memberikan manfaat untuk peningkatan kesejahteraan masyarakat disekitarnya.

Dalam pengembangan Geopark Tambora, dibentuklah Geoproduk yang bisa mendukung ekonomi lokal masyarakat. Geoproduk geopark Tambora yaitu Geouma, Geokuliner, Geotrekking, Geoherbal, dan Geotravel. Dalam kegiatan pengabdian pada masyarakat ini dilakukan pelatihan geokuliner terhadap kelompok ibu-ibu di Kecamatan Kempo dengan membuat interpretasi geologi terhadap geoproduk tersebut.

Dengan dilakukannya kegiatan pelatihan ini akan meningkatkan kemampuan masyarakat lokal untuk menyediakan geokuliner untuk pengunjung di Kawasan Geopark Tambora. Hal ini diperlukan karena jaraka yang panjang untuk mencapai Geoaprk Tambora \pm 6 jam dari bandara Sultan Salahuddin Bima.

\section{METODE PENGABDIAN PADA MASYARAKAT}

Kegiatan Pengabdian pada Masyarakat dilakukan di kawasan Geopark Tambora yaitu di Desa Kempo, Kecamatan Kempo Kabupaten Dompu.

Metode pelaksanaan Pengabdian Pada Masyarakat dengan tahapan :

1. Melakukan pelatihan dalam pembuatannya kepada kelompok wanita di Desa Kempo.

2. Melakukan pemberian nama sesuai dengan interpretasi geologi terhadap geokuliner yang dihasilkan

3. Pelatihan pengemasan geokuliner dan bentuk promosi yang bisa dipasarkan melalui Geopark Corner.

Kegiatan pelatihan geoproduk di geopark Tambora dilakukan dengan kerjasama dengan Dewan pelaksana Geopark Tambora dan Bappeda Provinsi NTB. Kegiatan ini dilakukan dengan melibatkan ibu-ibu di Desa Kempo dengan membuat kuliner khas Dompu yang kan dinamakan dengan interpretasi geologi untuk 
meningkatkan nilai promosi dan pengenalan budaya di Geoaprk Tambora. Dengan pelatihan ini diharapkan wanita dapat menjadi penggerak ekonomi di kawasan konservasi di tengah perubahan tata guna lahan akibat penanaman jagung.

\section{HASIL DAN PEMBAHASAN}

a) Mitra dalam kegiatan

Dalam kegiatan pengabdian pada masyarakat mitra yang terlibat adalah :

> Dewan Pelaksana Geopark Tambora : peran Dewan Pelaksana dalam kegiatan ini adalah sebagai fasilitator yang menghubungkan antara pelaksana Pengabdian pada masyarakat dan masyarakat di Desa Kempo, diman wilayah Geopark Tambora merupakan kawasan pengelolaan Geopark Tambora. Dewan Pelaksana juga menyediakan Geopark Corner sebagai media pemasaran geokuliner yang dihasilkan.

> Bappeda Provinsi NTB : peran Bappeda Provinsi NTB yaitu mendukung dalam biaya perjalanan ke lokasi Geopark Tambora.

$>$ Kelompok Ibu-lbu desa Kempo : merupakan mitra yang sangat berperan yang diberikan pelatihan dalam pembuatan geokuliner.

b) Pelaksanaan Kegiatan Pengabdian pada masyarakat

Kegiatan pengembangan geproduk di Geopark Tambora dilakukan dengan 3 (tiga) tahapan yaitu :

1. Melakukan pelatihan dalam pembuatannya kepada kelompok wanita di Desa Kempo. Dalam pelaksanaan pelatihan geokuliner dilakukan dengan melibatkan 5 (lima) kelompok wanaita di Desa Kempo.

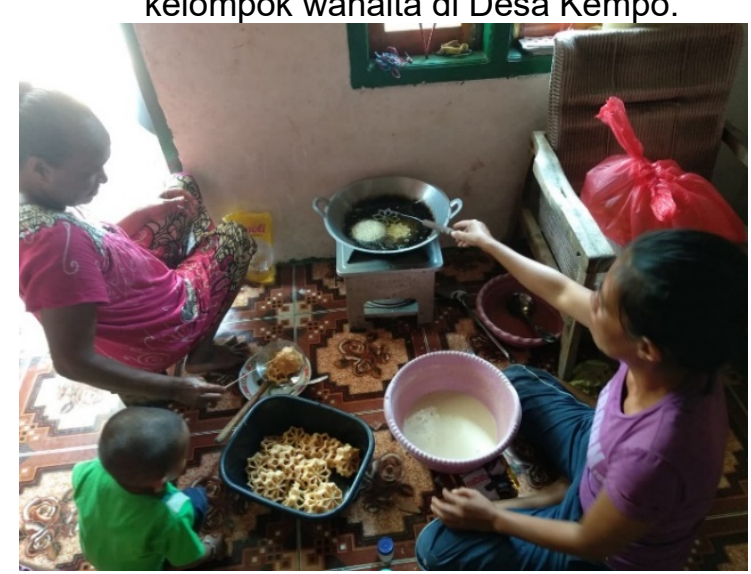

Gambar 1. Pelatihan Pembuatan Geokuliner

2. Melakukan pemberian nama sesuai dengan interpretasi geologi terhadap geokuliner yang dihasilkan. Adapun geokuliner yang dihasilkan dalam pengabdian pada masyarakat ini sebagai berikut :

a. Sponge Tambora (Kahangga) Sponge Tambora merupakan nama dengan interpretasi geologi yang berarti rongga, hal ini bisa dilihat dari bentuk yang berupa rongga-rongga. Sponge tambora merupakan sebuah jajanan khas dari masyarakat mbojo yang memiliki rasa manis. Sponge tambora merupakan jajanan yang akrab bagi masyarakat mbojo, sehingga merupakan kuliner yang khas yang patut untuk dilestarikan.

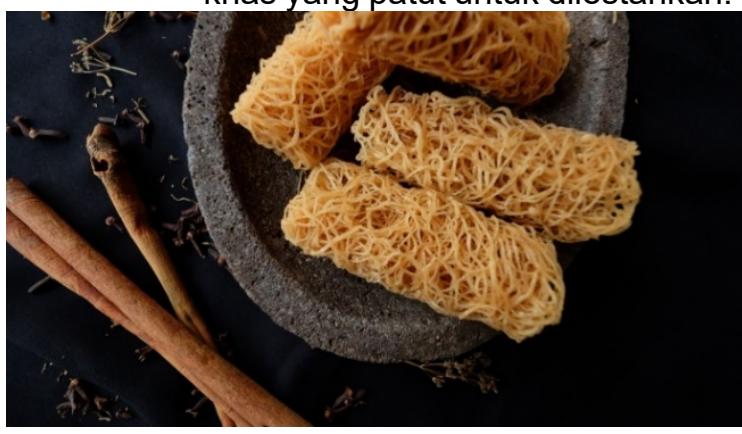

Gambar 2. Sponge Tambora

b. Sweet Doro bente

Sweet Doro Bente merupakan salah satu kue khas dari Mbojo yang memiliki citarasa yang manis. Sweet Doro Bente merupakan nama dengan interpretasi geologi. Doro Bente merupakan salah satu condercone yang berada di sebelah selatan Gunung Tambora. Cindercone merupakan kerucut sinder atau gunung api yang terbentuk lebih dahulu daripada gunung Tambora. Cindercone yang tersebar dikawasan Gunung Tambora sudah tidak aktif lagi. Ketinggian cindercone di kawasan ini sekitar 1000 mdpl. Doro Bente selain merupakan cindercone, tetapi juga merupakan situs kebudayaan yang diperkirakan merupakan benteng yang di miliki oleh Kerajaan Pekat yang hilang akibat letusan tambora pada tahun 1815. Hal ini bisa diketahui dari beberapa penelitian yang menemukan peninggalan di Doro Bente. Jajajan ini dinamakan dengan Doro Bente karena bentuknya menyeruapai bentuk morfologi dari Doro Bente. 


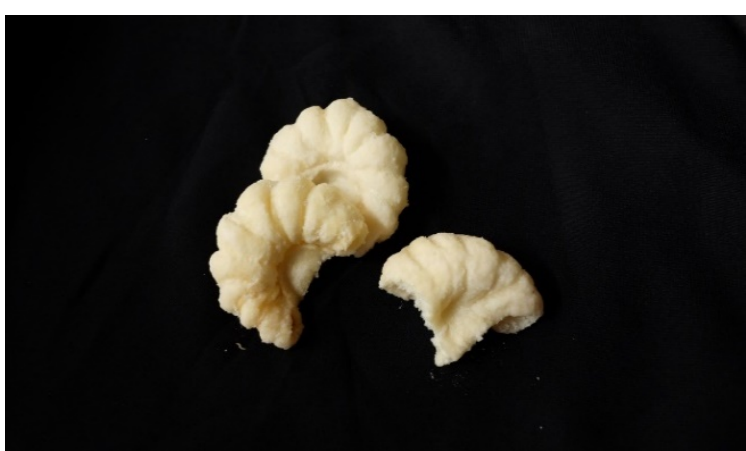

Gambar 3. Sweet Doro Bente

c. Fumarola Tambora

Jajanan ini merupakan jajanan yang terbuat dari jagung yang dijadikan dodol. Jajanan ini memiliki cita rasa yang manis, hal ini dikarenakan budaya masyarakat mbojo yang menyukai kue atau jajanan yang rasanya manis. Jajanan ini dinamakan dengan fumarola Tambora, hal ini karena fumarola merupakan asap yang dikeluarkan oleh gunung api aktif yang berwarna putih atau kekuningan.

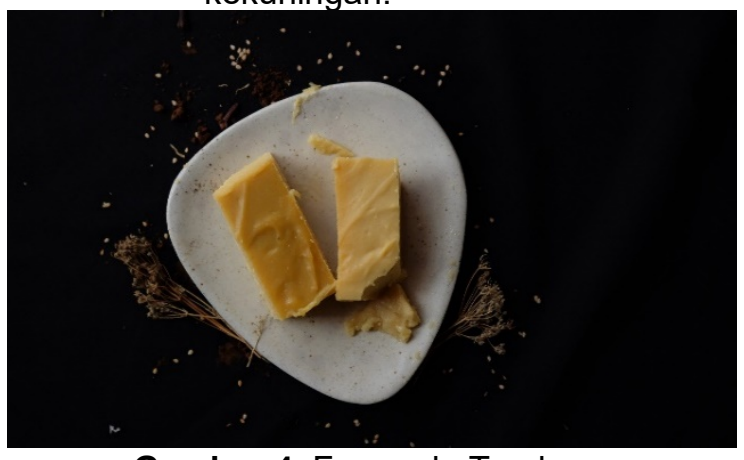

Gambar 4. Fumarola Tambora

d. Kopi Piroklastik Tambora

Piroklastik merupakan material yang berupa batuan maupun abu yang dikeluarkan pada saat Gunung Tambora meletus pada tahun 1815. Kopi yang digunakan oleh masyarakat berasal dari kopi yang ditanam di kawasan Desa Oi Bura di Pancasila. Kawasan ini merupakan kawasan yang subur dimana lapisan tanah setebal sekitar 3 meter merupakan lapisan piroklastik yang berupa abu vulkanik. Kawasan ini dipenuhi tumbuhan kopi, sehingga memiliki cita rasa yang khas.

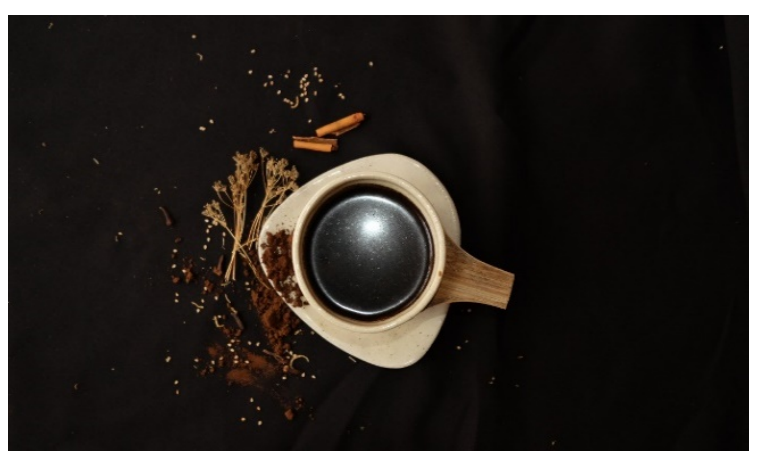

Gambar 5. Kopi Piroklastik Tambora

e. Spring Ho'do

Merupakan salah satu jenis masakan yang digunakan sebagai sambal yang biasanya disajikan dengan ikan. Spring Ho'do merupakan salah satu mata air yang berada di kawasan Tambora. Mata air ini merupakan mata air yang keluar melalui celah atau retakan batuan beku.

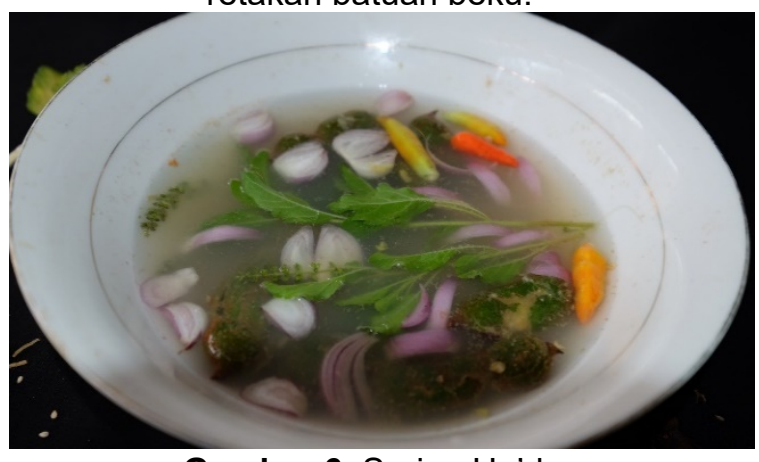

Gambar 6. Spring Ho'do

f. Kima Nangamiro

Kima Nangamiro merupakan salah satu masakan khas Mbojo yang terbuat dari Kima. Kima nangamiro merupakan salah satu lokasi kima yang terdapat di Teluk nangamiro dengan ukuran yang besar.

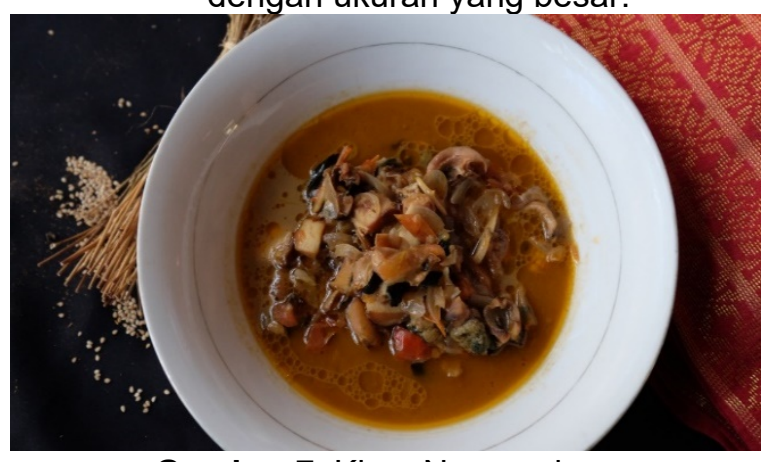

Gambar 7. Kima Nangamiro

g. Savana Tambora

Merupakan sambal yang terbuat dari mangga dicampur dengan asam yang biasanya banyak terdapat di kawasan tambora. Citarasa sambal ini campuran antara asam dan pedas dari cabe yang ditambahkan. Dinamakan 
dengan savana tambora karena bahan-bahan yang digunakan meruoakan tumbuhan yang biasanya terdapat di savana tambora. Savana merupakan morfologi dataran di lereng tambora yang dipenuhi dengan tumbuhan kerdil, berduri, daberdaun kecil.

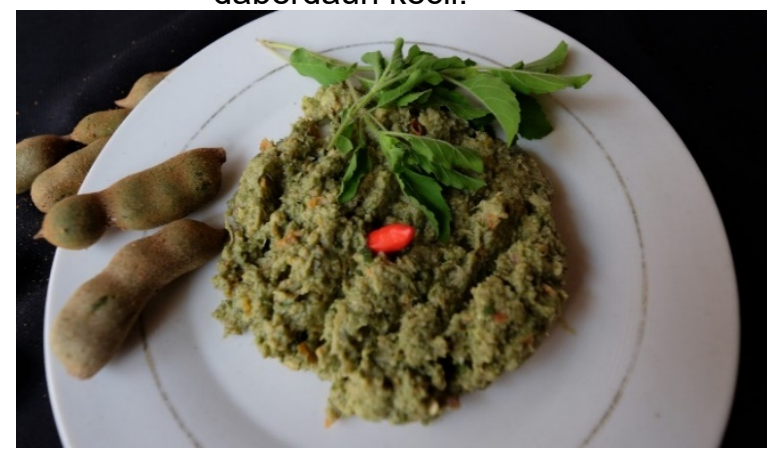

Gambar 8. Savana Tambora

h. Ikan sarae Nduha Merupakan jenis masakan yang dimasak dengan citarasa ama pedas yang merupakan kombinasi dari beberapa rempah khas masyarakat Mbojo. Sarae Nduha merupaka pantai breksi yang terdapat di Kecamatan Pekat.

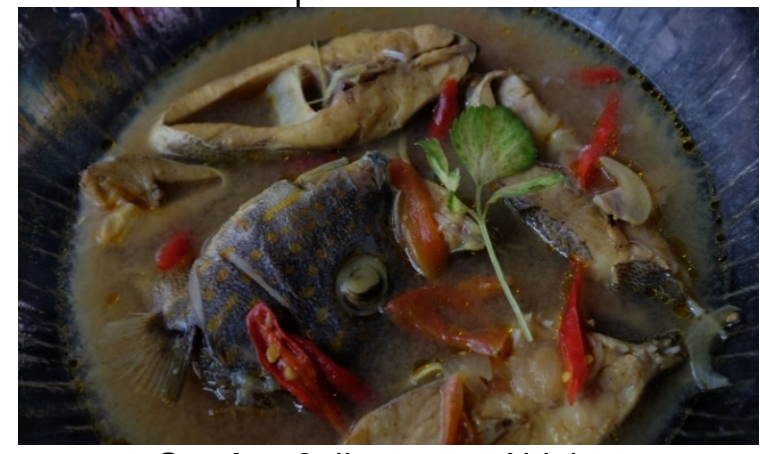

Gambar 9. Ikan sarae Nduha

i. Kawah tambora

Merupakan masakan khas Mbojo yang nama lokalnya adalah Kawoso. Masakan ini dinamakan dengan Kawah Tambora, dimana kawah merupakan danau yang terbentuk di dasar kaldera Tambora yang meletus pada tahun 1815. Ukuran kawah mengalami peningkatan dari tahun ke tahun.

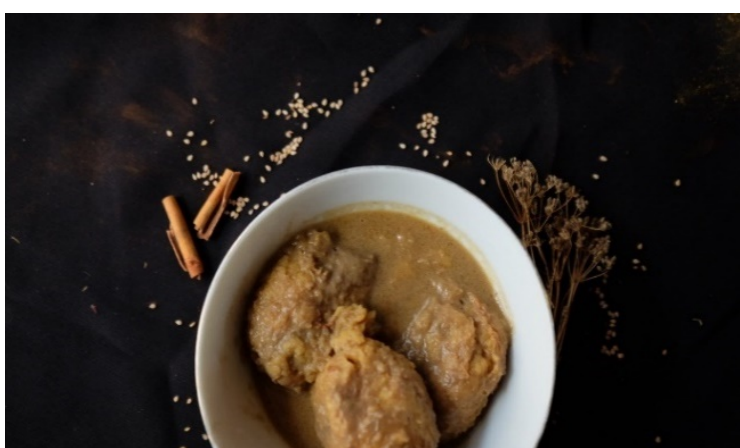

Gambar 10. Kawah Tambora

3. Pelatihan pengemasan geokuliner dan bentuk promosi yang bisa dipasarkan melalui Geopark Corner.

Pelatihan dilakukan dengan mengajarkan tata cara penampilan letak dalam menyajikan ketika dilakukan pemesanan, dilakukan pelatihan mempublikasi yang dibantu oleh Dewan Pelaksana Geopark Tambora melalui Geopark Corner.

\section{KESIMPULAN DAN SARAN \\ Kesimpulan}

Kesimpulan dalam kegiatan pengabdian pada masyarakat ini yaitu pengembangan geoproduk berbasis masyarakat lokal dengan interpretasi geologi yaitu :

a. Kegiatan pelatihan mendapatkan dukungan dari peserta pelatihan di Desa Kempo

b. Hasil pelatihan akan menjadi produk di Geopark Corner Geopark Tambora

c. Dengan adanya geokuliner diharapkan peran perempuan Desa Kempo akan

Saran mendapatkan keuntungan ekonomi

Saran dalam kegiatan pengabdian kepada masyarakat yaitu :

1. Perlu dilakukan pelatihan terhadap geoproduk lainnya

2. Perlunya dukungan Bumdes dalam menunjang kegiatan peningkatan peran perempuan.

\section{DAFTAR RUJUKAN}

Farsani, N.T.,Coelho, C., and Costa, C.,(2011) Geotourism and Geoparks as Novel Strategic for socio-ekonomic Development in Rural Areas. 68-81. http://dx.doi.org/10.1002/jtr.800

Fauzi, Noor Syafarinamohd and Misni, Akamah. (2006). Geoheritage Conservation : Indicators Affecting The Condition And Sustainability Og Geopark - A Conceptual Review. Journal Elsevier. Vol. 222 (2006):676-684

Azman, N.,halim, S. A., Liu, O.P., Saidin, S., and Komoo, I., (2010). Public Education 
in Heritage Conservation for Geopark Community. Jurnal Procedia - Social And Behavioral Sciences 7 (2010) : 504-511.

Doi:Http://Dx.Doi.Org/10.1016/j.sbspro. 2010.10 .068

UNESCO. (2004). Guidellines and Criteria for National Geoparks seeking UNESCO's assistance to join the Global Geoaprks Network (GGN)

Tim Penyusun. (2017). Dossier Geopark Tambora. Bappeda Provinsi NTB 